\title{
Integrating the Business and People Dimension of Change at Safaricom Limited Plc, Kenya
}

\author{
Thomas, K. Bwaley \\ Safaricom Ltd Plc, Kenya. \\ Vincent, N. Machuki, PhD. \\ School of Business \\ University of Nairobi
}

\begin{abstract}
Organizations seeking to be relevant and achieve sustainable competitive advantage in a changing business environment initiate and successfully implement change programs. All change initiative must address both the business and the human sides of change, and their integration is important for success to be realized. This study sought to determine the integration of business and people dimensions of change at Safaricom Limited, a leading cellular services provider in Kenya. To achieve this objective, data were obtained from six senior managers through comprehensive structured interviews. The findings of the study revealed that Safaricom Limited has embraced integration of business and people dimension of change through employee involvement in change formulation, proper feedback mechanism using employee survey and staff council which has resulted in successful implementation of change with very limited resistance while having sustainable profitability. The study's implications for policy have been advanced based on the study findings. The study concludes that in the current turbulent environment, learning organization must integrate the people dimension of change with the business dimension of change to remain competitive both in service delivery as well as being an employer of choice and as a partner of choice in business. The study is limited to Safaricom Limited and the findings may not apply to other players in the mobile telephony industry. Based on this limitation, suggestions for further research have been put forth.
\end{abstract}

Keywords: Business Dimension of Change, People dimension of Change, Safaricom Limited

\section{Introduction}

According to Business Week (1992) special edition, "change can no longer be an occasional episode in the life of a corporation. Companies with rigid structures will be swept away. Corporate cultures that can adapt will survive and thrive..." (p.60). According to proponents of behavioral approach, if managers understand their people and adapt their organizations to them, organizational success will usually follow (Certo \& Certo, 2009). Organizations confront change due to changed circumstances; success of the change initiative within the organization can only be realized if and only if the people and business aspects of change are well integrated. Contingency theorists have based their approach on Systems Theory, adopting the premise that organizations are open systems whose internal operations and effectiveness are dependent upon the particular situational variables they face at any one time, and that these vary from organization to organization (Burnes, 2009).

Most organizations know their businesses, and the strategies required for success. However many struggle to translate the theory into action that will enable the strategy to be successfully implemented and sustained while others fail to transfer the strategic choices into operational actions, and to truly motivate their people to work with enthusiasm and cohesively towards the corporate aim. On the other hand business environment is changing faster than ever before, new technologies are emerging constantly at an increasing velocity, and industries are shaken by deregulation and new entrants while some adapt others fail. Having executives and employees change their thinking, beliefs and behaviours is demanding and difficult. This is because change is a complex, multi-stage process rather than a silo event (Kotter, 1995) and much has to be done to create a sense of urgency, win support, and silence cynics. Safaricom Kenya limited has been fraught with myriads of changes both systemic and people aspects. 
In order to achieve excellent performance organization are told to rationally analyze their situation and adopt change which is most appropriate for the contingencies they face, they have to align themselves with their size, technology and environment. For this to be realized change in organizations has two critical dimensions, business dimension and people dimension. Successful change happens when both dimensions of change occur simultaneously. Safaricom like many organizations has in the past designed business solutions, developed new process and repeatedly done massive restructuring. What stirs ones curiosity is how business dimension and People dimension of change has been integrated at the company.

Previous studies have not addressed the integration of business and people dimension of change which hypothetically could be the drivers of results obtained in the above mentioned studies. In the current global business regime the relationship between people and business is becoming a perceived key factor in the success of organizations. While researchers have delved more on business dimension and some on people dimension of change independently, integration of business and people dimension of change is an area that is yet to be studied. Study on the relationship between systemic and behavioral changes needs to be undertaken to give a scholarly direction on the impact of the twin dimensions on change management and success of organizational changes. Therefore this study sought to address the extant information lacuna with regard to the extent of integration of the business and people dimensions of change. To what extent have people and business dimensions of change been integrated at Safaricom Limited, Kenya?

\section{Literature Review}

The theories underpinning this study are Open System Theory and ADKAR model (Hiatt, 2006). According to Kotter (2001), a central feature of modern organization is interdependence, where no one has complete autonomy; employees tied to each other by their work, technology and hierarchy, presenting a special challenge to change process, and requiring alignment of people. Senge (2006) observed that the limits of growth and organizational learning often frustrated organizational changes. Kaplan and Norton (2006) argued that continual search for organizational form is driven by changes in nature of competition and economy and Kaplan (2007) argued that the world is constantly changing as business evolves, new products and distribution channels emerge, requiring changing the people and incentives, tangible resources, and operating style.

Hiatt (2006) argues that if you are an employee in an organization undergoing change, your reaction to the change and how you are viewed by the organization will be directly affected by each of the five elements in the ADKAR model of awareness, desire, knowledge, ability and reinforcement. According to Creasey (2007) when you introduce change to the organization, you are going to be impacting on system, process, organizational structure and job roles. He further establishes that the change typically results as a reaction to specific problems or opportunities the organization is facing based on internal or external stimuli with the intention of becoming more competitive or becoming closer to the customer or becoming more efficient. How these interaction are handle in the business dimension or people dimension of change determines the organization competency to meet the external and internal requirements and successfully navigate through the desired changes.

According to Hiatt (2006) when a group undergoes a change, it is not the organization that changes, but rather the behaviours of individuals, this change in collective behavior is what produces different outcomes for the organization. He further notes that Organizational change management and individual change management must be used together to manage change successfully, thus the development of ADKAR model which focuses on change at an individual level, and the specific needs of that individual, in order for that person to change their behaviours to the desired ways of working, the new culture. The ADKAR Model reflects the necessary building blocks for individual change which entails awareness of the need for change, desire to support and participate in the change, knowledge of how to change, ability to implement the change and reinforcement to sustain the change (Hiat, 2006). The ADKAR model is that link between individual performance, organizational change management and business results.

According to Todd (1999) change management is a structured and systematic approach to achieving a sustained change in human behaviour within an organization. Lewin (1951) argues that there are forces that drive change and those restraining it, where there is equilibrium between the two sets of forces there will be no change. In order for change to occur the driving forces must exceed the restraining forces. Managing change requires consistency of approach and constancy of purpose. There are two tasks that successful change programs have to achieve, the change management process, focusing on the process steps in the change management project plan and the transition of people, providing successful change in individuals and changing their behaviours to a new desired 
state. Nadler (1998) argued that real change in real organizations is intensely personal and enormously political. Change processes entail not only structures and ways of doing tasks, but also the performance, expectations and perceptions of all involved parties.

Change in an organization may face systemic resistance occasioned by passive incompetence of the organization to change, whereby the system as a whole reject an attempted change, even if that change is promoted over a long period of time by a substantial fraction of the population. This may be attributed to among other factors current organization design, organizational culture, resource limitations, fixed investments and inter-organizational agreements. Systemic resistance occurs whenever the development of capacity lags behind strategy development or when there is a disjointed interlinks.

There are lots of reasons why people may be hesitant about changing the way they do things. Hiatt (2006) argues that under ADKAR Model situation awareness principle requires that executives and employees be set in their organizational contexts to understand the situations, recognize and accept the need to change. They have to be convinced of the reasons for change and understand what is in it for them and the consequences if change is not enacted. The desire to support and take part in the change is dependent on the nature of change, credibility of the driver of change, intrinsic factors and history of the organization. Therefore the employee should be motivated to desire change. The people should be given the knowledge of how to change and what to do to make the desired change happen, this can be achieved through training, seminars and knowledge transfers. Ability to implement the change is then developed by providing the skills to implement change on a day to day basis through daily involvement, access to subject matter experts and hands on job training. To keep the change in place reinforcement is essential, by creating an environment to sustain the change through celebrations, recognition, rewards, feedback to and from employees, audits and performance measurement systems. Organizations that desire a clear articulation of what they want to change and desire to make it happen would integrate the Business side and the people side of change to provide a smooth and homogeneous transitioning.

Saratoga (2010), argues that it is not people that are the greatest assets to an organization, but the relationship with them. Progressive companies work hard at creating environment in which ideas and suggestions bubble up from below and employees are made to feel that their views and suggestion count. Kotter (1995) found that, it is possible for the resistance to be sited within the individual, but it is much more likely to be found elsewhere in the system. Weinrich, Cannnice and Koontz (2008) established that involvement of organizational members in planning change can reduce uncertainty and communication about proposed changes also helps clarify reasons for change. Organizational Culture can impede or facilitate change, therefore it is necessary to examine the cultural fit with the strategic change and ensure the two are synchronized. . According to Senge (2006), people excel and learn when there is a genuine shared vision and not the familiar traditional vision statement. According to Weinrich, Cannnice and Koontz (2008) concept of harmony of objectives, individuals have personal goals that are different from organizational goals but these can be harmonized. For an organization to successfully implement change, it must be change-ready, meaning that the people and structure of the organization are prepared for and capable of changing in harmony. Successful people integration should include a change management program to help companies motivate, retain, and acquire pivotal talent (PricewaterhouseCoopers, 2013).

\section{Methods}

\section{Study Design}

A case study was chosen as the research design for the study to allow for an in-depth examination of events and phenomena within a real-life context for purposes of theory development and testing. Key was the fact the study was conducted in a single namely, Safaricom Limited and the desire was to collect in-depth information along the key themes of the study. Case study design allowed the researchers to study the complex relationship between phenomena, context, and people. The case study was on determining the extent to which business and people dimensions of change have been integrated at Safaricom Ltd.

\section{Data collection}

The main source of data for the study was primary qualitative data that was captured using a comprehensive interview guide. The interview guide was developed along the study objectives and administered through personal interviews. Personal interview was chosen because the researcher would be able to ask respondents questions to get required answers and incase of any ambiguity it would be corrected immediately thus high flexibility, excellent opportunity to probe further with a high response rate. 
The interviewees were director strategy and innovation division, two heads of department, two change champions and one staff working on strategy division on implementation. The researcher conducted direct and personally administered the interviews. The direct personal interview method was preferred in this case study, so as to obtain in-depth information from the respondents and clarifying any issue not clear to the respondent for an accurate information gathering. The interview guide was designed so as to identify how business dimension of change has been integrated with people dimension of change in Safaricom Limited.

\section{Study Variable}

The study variables were the business and the people dimensions of change. Business dimension of change is the fundamental changes in the business of the organization and its future direction. Hiatt (2006) established that business dimension of change includes identifying the business need or opportunity, defining the project (scope and objectives), designing the business solution (new processes, systems and organizational structure), developing new processes and systems, implementing solution into the organization and post implementation evaluation. Areas of concern entails analyzing what aspects of the organization will be affected, how significant are the alterations to status quo, how long will the change process last and how much will be the departure from the current business scenario.

The people dimension is concerned with how employees and stakeholders experience the process of change. The importance of embedding the people dimension of change to organizational behavior is attributed to the changes undertaken in order to avoid behavioral resistance. People dimension of change involves the alignment of the organization's culture, values, people, and behaviours to encourage the desired results. Effective management of people dimension of change has been defined by Hiatt (2006) ADKAR model as requiring managing five key phases namely, Awareness of the need for change, Desire to participate and support the change, Knowledge of how to change, Ability to implement the change and Reinforcement to keep the change in place. This process is said to be sequential and therefore, it is not possible to achieve success in one area unless the previous action has been addressed effectively.

\section{Data Analysis}

The study gathered data that were largely qualitative in nature. Therefore, qualitative methods of data analysis were used and the preferred qualitative method was content analysis technique. It captures a qualitative picture of interviewees concerns, ideas, attitudes and feelings. This is a technique of making inferences by systematically and objectively identifying specific characteristics of messages as the basis to relate trends (Nachmias and Nachmias, 1996). The nature of the data to be collected from this study was from direct personally administered interviews targeting the specific individuals drawn from top and middle level managers of Safaricom Limited. The in-depth understanding of the responses from the respondents was used in the analysis and interpretation of the data. Organization's changes was categorized, and analyzed as systemic/business dimension or people dimension of change. The extent to which the dimensions of change were integrated was then be deduced.

\section{Findings}

\section{Organizational Changes at Safaricom Limited}

The study interrogated interviewees on whether there was a strategic change program adopted by Safaricom Ltd in the recent past. On interrogating strategic change at Safaricom Ltd., an interviewee observed that: "Safaricom undertook a strategic change by shifting from focusing on wide coverage and capacity to focusing on being the best network in Kenya (BNK), not just best by our standard but as measured by independent bench marks as well as net promoter score based on customer opinion". This according to the interviewee came after discovering that the success the company had in the first ten years could not navigate it through the highly competitive sea of mobile industry as a mobile network operator. The interviewees observed that Safaricom joined the industry after Kencell, currently Airtel, with its previous strategies suited as a follower in the market and therefore the interest was on rolling out as many sites as possible for wider coverage, hence the famous adverts such as Safaricom is now in Naivasha and Safaricom comes to Meru. This earlier strategy was noted by the interviewees to have been focused on expansion of infrastructure, network coverage and customer market share, thus the company's vision was to be the best company in Africa. 
For which the interviewees said the company achieved by being the mobile network operator with largest market share, then becoming second most profitable organization after EABL and thereafter the leading tax payer in the country. The strategic shift therefore was from focus on infrastructure fit to customer based business focus by looking more on the customer experience than the network coverage area.

According to the respondents Safaricom undertook strategic change by putting the systemic structures in place. The respondents were in agreement that the first phase was in employing a new CEO from outside the company indicating the beginning of a new dispensation and giving the change credibility among employees. This was followed by restructuring that involved re-organization of all functional and operational levels with leadership teams put in place. Having put up the critical structures that gave the skeleton of the re-engineered Safaricom, the interviewees observed that a new vision statement was established of 'Transforming lives'.

According to the respondents Safaricom realized that it was operating in an open system, whose success in a stiff environment would depend on the feedback from internal and external reaction and how the feedback would be processed for the company to gain a competitive advantage in the industry. From the external environment the respondents indicated that Safaricom did not initially focus on customer experience but rather capacity, expansion and new technology but interrogation of aspects showed that to be the best network was a derivative of being valued and to be valued involved managing customer feelings, expectation and delivering simple products. Therefore, Safaricom established a new strategy shift from focusing on infrastructure expansion to focusing on people driven by the mission of transforming lives, with a key focus on putting the customer first and being obsessed with the subscriber needs. The company emphasized on having the customer facing entities to effectively and efficiently manage the clients and stakeholders expectation and process their feedback and request with speed, simplicity and trust that ultimately grew to be the business culture dapped Safaricom way.

\section{Business Dimension of Change at Safaricom}

On interrogating the interviewees on what changes have taken place at Safaricom Kenya ltd concerning the business dimension, the respondents highlighted that until 2011 Safaricom bread basket in revenue streams was on voice calls but then challenges arose threatening the revenue streams locally through price wars leading to fall in calling rates from Kshs 12 to Kshs 4 per minute charge. Respondents also indicated that a global challenge arose on voice calls through customers using alternative option of international calls other than GSM such as voice over internet protocol like Skype calls and termination of international calls through SIM boxes.

With these challenges choking the business profitability the respondents said that Safaricom sought for alternative revenue streams to focus more on so as to back up the traditional business of voice calls, the focus was therefore, directed to Mpesa, data and collocation facilities. According to the interviewees Mpesa service that was introduced in March 2007 originally seen as a mere values added service to customers, was re-engineered to be a transformative sector in Safaricom business. Making the then pure person to person transaction evolve into person to business and thereafter business to person transaction on boarding corporates in Mpesa use through Lipa Na Mpesa, pay bill services, mobile banking thus resulting in a major strategic inflexion point and changed how Safaricom and society transacted business and the national economy shifted as well. Further the business has planned to transfer the entire Mpesa platform infrastructure from Europe to Kenya through G2 project plan.

According to interviewees over-focus on data was also introduced with the mission of democratizing data so as to have all mobile users with data enabled phones to be able to access internet. This shift resulted in 15,000 to 17,000 subscribers accessing internet for the first time every day in the period 2010 to 2011, deepening information inclusion across the country a transformative strategic move. Also the respondents said there was a new focus on enterprise business unit especially on small and medium enterprise. Safaricom spoke to their needs by providing a shared infrastructure in the form of cloud computing, domain / hosted services and conferencing services. According to director strategy Safaricom got some traction having seen the benefits and the opportunities for being partner of choice in business to the SMEs. The respondents indicated that for Safaricom to retain its profitability and market lead restructuring, shift in target market, change in policies and mission was inevitable thus a new CEO and a new CFO were recruited externally. With a new chief executive officer on board Safaricom re-engineered its business strategies towards customer focus by way of restructuring in which the earlier functional structure characterized by commercial and non- commercial arms were organized into customers facing profit centres which comprise of financial services, consumer business unit and enterprise business unit divisions and non-customer facing corporate centres like technology, customer care, risk management, resources, finance, corporate affairs, marketing and strategy and innovation divisions. 
An interviewee argued that this was essential for clear identification of customer touch-points to enable the business feel the customer and therefore supply optimum value to the customers, becoming more agile and responsive to customers and doing everything possible to be seen as a partner of choice.

The respondents said that there were fundamental changes in the future direction of the business with target market shifting to the young generation who would be tomorrow's high end users and therefore products were rolled out targeting the youth. The company's vision was also changed from the slogan 'to be the best company in Africa' to 'transforming lives' and everything else being implemented at Safaricom was to be done with the eyesight of transforming lives.

The respondents further indicated that Safaricom introduced a new robust and aggregated process for change management known as service management suite used to manage all service requests, reporting of incidences and corrective actions, defining SLAs and timelines and tracking of incidences and process. In this platform all actions must be logged in detailing the procedure to be undertaken, fall back plan, service impact, actionee and planned execution time. The changes raised were said to be discussed by a committee before action to avoid situation where two service affecting changes are run concurrently thus aligning all activities in the business. This system also was observed to provide avenue for problem management and track of recurring issues which deserve high level expert handling for escalation with an automated escalation of incidences of failure to close within period.

\section{People Dimension of Change at Safaricom}

When respondents were asked what changes have taken place at Safaricom Kenya ltd concerning the people they said that the first thing done was to bring in a new leadership face in the form of a new CEO and a new director of resource to provide a fresh prism of handling human resources. According to the respondents as an organization you can have the best technology, the best rules but without a genuine relationship with the workforce everything else will lose its value. The respondents indicated that the new CEO shared his vision assuring employees that he came for the better of Safaricom as a whole and not to send employees home.

The interviewees observed that communication and assurance from the CEO to the senior management team and employees that the changes in leadership would be done in a competitive process was essential. In addition Safaricom recruited an independent consultant to guide through the interviews and change process, this indicated that the CEO was ready to work with all without preferences, a key preparation on people aspect of the change and this consistency of purpose was said to have provided trust through the change process.

According to the interviewees work groups were formed for instance in technology division, the groups analyzed how divisional restructuring was to be done. The work groups were constituted by representatives from all existing sections and their role was to seek employee opinion and come up with a more lean, effective and efficient structure. These created a sense of ownership in the restructuring of the division and desire to have it work with models tested and interrogated before flouting it for application. Series of town hall meetings, workshops and forums were then held to sensitize the employees and obtain feedback on the intended proposed changes. Campaigns were finally made through emails, posters and branding of website to Safaricom tech 2.0 with idle computer and laptop windows displaying the re-alignments as screen saver. The interviewees further identified that 'skip level' meeting were organized by the CEO and directors whereby the chiefs or the CEO would visit employees in their workstations directly without being accompanied by HoDs or senior managers for direct interaction and sharing of opinions and concern with CEO in person. In your shoe program was also introduced where the management team went to the workstation and performed the normal duties of employees so as to have a feel of the daily experiences of the employees and thereafter cross-sectional in your shoe program to enable employees have the experience of other teams. According to the interviewees the 'skip level' and 'in your shoe' programs provided a platform for having a unified obsession of delighting Safaricom customer by harmonizing cross-sectional objectives and SLAs under the banner of speed, simplicity and trust that is Safaricom way. Under the new regime the interviewees identified that Safaricom changed how it carried out employee satisfaction program by way of introducing people survey in which employees rated managers based on people management index and satisfaction index to gauge employee perception of how their managers engage them and with what suggestion they have for Safaricom to be an employer of choice. The employee survey score was said to contribute to the manager's calibration score on performance at the end of the year imposing managers to change how they relate with staff under them. 
Another people aspect the respondents gave was the change in the working culture where people moved from a motto of I deliver no matter what it takes to delighting the customer. Therefore, the entire Safaricom system became synchronized with all subsystems in the form of people and work groups being obsessed with customer needs providing a seamless hand over of functions towards giving the best service to the customers from the service retail desk to the best network and to excellent value added services all geared to making the customers happy. Employees were encouraged to change their mindset from seeing customers as source of problem to looking at them as the spring of revenue and as an indirect employer without whom they will be no Safaricom and thus no employment opportunities. Attitude towards the customers was given a fresh positive look as a reason for the company's existence and as such a mutual relationship was essential to build between partners, customers and employees, targeting a better customer delight index score.

\section{Integrating people and business dimension of change}

According to the interviewees for any successful change to be realized the business dimension and the people dimension had to be in tandem. An interviewee indicated that Safaricom under the new dispensation emphasized on a symbiotic relationship between the people and the business, with the realization that having a motivated staff resulted in high retention of the best minds and elimination of resistances to change. Further, identified that service provision was not like goods delivery as the emotional status of the service desk representative determines the clients perception and intake of the value of the service hence having a happy staff goes a long way in providing customer satisfaction as negative presentation at the call center or retail shop will be too late to correct the resultant damages unlike goods which can easily be recalled.

Interviewees observed that for Safaricom to realize speed, simplicity and trust as Safaricom culture, the business had to intervene on cares and concerns of issues which interfere with employee concentration at work. The issues identified included personal development, financial independence, career and academic development, social matters especially for post-natal care, health and fitness and compensation for extra working hours meant for personal life. On personal development the respondents said Safaricom provided mortgage arrangements, car loans at highly competitive rates and free parking for staff. On financial independence the company brought in investment consultants to advise employees on ways of achieving financial independence, employees were given employee stock ownership plan (ESOP), investment opportunities given through Safaricom investment cooperative (SIC), Safaricom SACCO for staff to be able to own property while others follow the logistical requirements. Safaricom provided dual career path to allow all employees have equal opportunities for growth and therefore people did not have to wait to be managers to move up the leader but through their involvement would move up as specialists. Sending staff to other countries through exchange program with Vodafone group members provided career growth as well as import of best practices for mentorship and ultimately lower support costs as the skilled force would be up to the task. Introduction of Safaricom resource center provided room for a wholesome academic growth providing access to information in all fields of learning within the premises and therefore staff spent more time in the office and login into the resource center libraries at free times.

On wellness and social matters it was observed that Safaricom provided medical cover for entire nuclear family, annual health clinics to check on personal health status. In addition parents with young children were provided with day-care/crèche facilities at work place where their young ones will be taken care off while the parents perform their duties in the offices, this gave full relieve to the mothers and added concentration coupled with peace of mind was realized among them. Recreational and fitness facilities such as gym were provided at affordable rates. Flexi working hours, telecommuting and teleconferencing options were introduced to allow staff do what they are meant to do effectively, efficiently and conveniently for greater output providing a staff friendly environment.

Further, the respondents said that Safaricom provides overtime and call out payments for work done out of the normal working hours, bonuses and salary review given annually based on employee performance and provision of transport facilities when working out of normal working hours and stations with travel allowances where applicable. When employees are transferred to new station relocation allowances are provided to meet the expenses of migration and settling in the new environment.

On recruitment and restructuring the interview observed that the company put up a high threshold for qualification of its senior staff and all position advertised so as to obtain a people who match the new expectation and challenges. Existing and new applicants went through an open interview process that selected only those with suitable skill set, energy and aptitude for continuous learning to meet the needs for a renewed Safaricom culture. 
In the restructuring, emphasis was put on placing people in the right places matching their skills, interest, passion and trainings to the positions they will hold.

When respondents were asked how Safaricom ensured employees transitioned successfully through the change, they observed that all staff were involved in the change process and were given opportunity to share their views on things they would like the business to do for them in order to serve the customers with speed, simplicity and trust. A staff council was set up for staff to get their representatives raise in the council session any arising concerns from the change that needed to be addressed by senior leadership with meetings held every quarter to respond to the voices of the employees from all divisions.

Further the interviews observed that an open door policy was implemented with all cubicles for senior managers brought down to create a common environment with employees on their work stations and activate a free flow of information either formal or informal resulting in relaxed relationship with management. People management was observed to contribute to $20 \%$ of manager's performance rating. In this regard one of the interviewees said:

"If you have engaged employees they will deliver more than employees who are there just to earn salary. Most often the reason why people leave a company is not pay but because they are leaving their managers".

Systems were put in place to lock events into the new order of business and regular audits done both internal and external to keep check of activities and mitigate on reverting to the old ways of doing business. Behavioral functional ethics were introduced of speed, simplicity and trust and this emphasized through Safaricom people development program (SPDP) offered in three categories namely Safaricom employee development program (SAE) for entry level, Safaricom manager development program (SAM) for middle level and Safaricom leader development program (SAL) in advanced level, these were used to equip the employees in all aspects of service delivery and personal development for sustaining a strategic advantage over the long term. This program according to the respondents was geared towards having a shared way of doing things in Safaricom and develops a high performance organization.

Interviewees observed that for organization to successful implement change all parties must be change ready as a team. Safaricom aligned all divisional strategies to the corporate strategy of customer focus and same was cascaded to individual objectives taking the customer as king and his delight was to be the joy of Safaricom as a whole. Key was delivering what you have promised to the customer with speed, simplicity and trust. All employees were involved in driving change from lower layers to upper layer of leadership hierarchy. Open door policy was embraced by management destroying the silos and doing away with VIP lifts, closed management offices resulting in accessibility by all to all and sharing common amenities among all employees despite their ranks. This provided an avenue for sharing ideas between management and employees and between teams creating an organizational climate optimum for change.

Forums for innovators was also introduced, where according to the respondents, initially ideas came from above but in the current regime an innovation forum dapped Zindua café was formed by strategy and innovation division where employees would post their ideas via internal Zindua café portal, screening will be done by innovation team to check for duplicates, vetting and scoring using pre-defined metrics is done and then successful ideas are adapted. This provided a sense of appreciation to the employee skills and the company as well obtained new products internally.

Employee survey was carried out to enable senior leadership understand what employees felt about the company and what their expectations were. Issues raised were dealt with such as employee work life balance thus provision of flexi working hours, salary reviews to cushion staff over inflation, recreation facilities, ESOP and simple dress code- smart casual implemented. Staff who felt negatively affected by the change went through counseling processes to align their attitudes to what change was meant for, transforming lives. Trainings were organized not only for hard hand skills but also soft life skills such as personal finance and personal healthy living across the company divisions. Respondents noted that with this kind of equipping it was easier for change to be adopted and implemented as employees felt that they were part of the organizations resulting in a quick buy in to support change.

\section{Discussion of Findings}

The research established that for a successful implementation of a strategic change, for any systemic change there must be an equal behavioral change at the same time otherwise resistance will take place. 
The behavioral change required must be symbiotic in nature, where the people involved in the change perceive and actually receive personal gain and development while the organization obtains behavior that supports the changes and delivers the corporate agenda. This agrees with Alkaya and Hepaktan (2003) observation that successful changes require effective communication, in which concerns and expectations flow easily up and down the organization. Further arguing that there should be a climate of trust in the organization, especially between workers and management, which will help them cope with the risk, uncertainty, and fear that often accompanies organizational change.

The study observed that Safaricom was operating in an open system, whose success in a stiff environment would depend on the feedback from internal and external reactions and how the feedback would be processed for the company to gain a competitive advantage in the industry. During the study it was found out that when Safaricom employees understood that the changes were meant neither to punish nor witch hunt but for the common good of the company's and employees' prosperity, change was then embraced. As regular and clear communication was provided through forums, road shows, question answer sessions and workshop greater support for change was realized with increased attendance to feedback session and participation in staff survey. This collaborates with Boohene and Williams (2012) findings that quality of information exchanged between management and employees has a significant effect on resistance by employees to organizational change.

The research established that in an open system the interface between an organization and the external environment require a greater integration of people dimension of change and the business dimension of change to achieve desired result. In the case of Safaricom the roles of the customer facing sections became one of the major objectives of the top level management to enable customers perceive Safaricom as a partner of choice and employees being appraised with customer delight index being part of every employee KPIs. Similarly Creasey (2007) established that the change typically results as a reaction to specific problems or opportunities the organization is facing based on internal or external stimuli with the intention of becoming more competitive or becoming closer to the customer or becoming more efficient.

On integrating business and people dimension of change, it was established that people dimension of change is not only how employees behave to and in the organization for change but also how the organization handles its staff for the employees to feel appreciated, honored and valued. Through personal development seminars such as managing your finances and staff people development program, use of flexible schedules such as telecommuting where individual can remotely work from any station without coming to the office, flexi working hours for those who think they work better early to report to work early and leave early while others report late and leave late provided an impressive avenue for optimum working times. This was found to have built a relationship of trust between the employer and employee catalyzing the output of the employees. This supports Hiatt (2006) observation that when a group undergoes a change, it is not the organization that changes, but rather the behaviours of individuals, this change in collective behavior is what produces different outcomes for the organization

Respondents said that integrating people and business dimension of change had given Safaricom competitiveness as employee work at their optimum, delivering services at their fullest of abilities and know how. Safaricom has become an employer of choice attracting great minds where everyone wants to work for and with Safaricom ltd. It has also enabled the company to retain the best skills within the market, thus guaranteeing skill continuity. For organizations to successfully implement change it was observed that credibility of the messenger is critical, publicity and communication must be done, staff should be involved from the beginning then through preparation to implementation, equip the staff with necessary skills for change, allocate adequate budget, allocate reasonable time to implement change and periodical progress measured through feedback from which results and corrective actions shared with all employees on current ratings verses expected targets.

It was established that people will either embrace and support change or resist change and like one steel company that said that our business is steel but our strength is our people. This indicates that the power of an organization is the type of people it has and the skillset coalescing around them.For successful change all individuals need to make a personal decision to support and participate in the change taking a concerted and on-going effort to make change stick. Therefore, if you are an employee in an organization undergoing change, your reaction to the change and how you are viewed by the organization will directly affect change management in line with Hiatt (2006) ADKAR model suggestion that successful change happens when both dimensions of change occur simultaneously. 
The study has given an in depth understanding to the view that organizations are open systems consisting of various subsystem. It was observed that the forces that necessitated change were external in nature and to deal with them required a change in internal environment and regular analysis of feedback. The forces of change included high level of industry competition, desire to match the ever changing demands of informed and learning customers and the knowledge that the status quo could not sustain the revenue growth further. Even in the same organization everyone does not hear about change at the same time and everyone does not process change at the same pace therefore, buy-in to change becomes an individual commitment and thus successful strategic change occurs only when each person is able to transition successfully.

This study has shown the significance of ADKAR model concept in integrating people and business dimension of change. It was observed that engaging employees through the change process by way of making them aware why they need to change, what is in it for them and training them to be ready for change with providing essential budgetary allocation for change provides a smooth transition through the change period. By rewarding those who go beyond their means to deliver, recognizing best efforts and compensating sacrifices made reinforces change. This also encourages positive feedback with the desire of having corrective measures for improved and better service delivery.

\section{Conclusion}

For an organization to successful implement change all parties involved must be change ready as a team and for any successful change to be realized the business dimension and the people dimension must be in tandem. The business must look down and reach the needs of the employees and the people must look up and pick the goals of the organizations for a mutual gain. The relationship an organization has with the people determines the extent in which the organization achieves its mission. The relationship is built when the level of trust increases derived from regular communication and working closely together bound by a similar objective. For an organization to have a homogenous objective between people and the business and across the business units, all institutional subsystems must know and have the feel of what other workgroups are doing. This gives a conscious actioning of roles to support the roles of other work groups up the value chain. There cannot be success in an organization where subsystems and the business as an entity work in isolation of the people needs. A relationship of trust between employees and the business and across building units is the key that unlocks an organization's potential.

The study revealed that integrating people and business dimension of change is paramount in management of strategic change and for the establishment of a team spirit that contain a competitive advantage to overcome negative internal and external forces. Communication, communication and communication is essential in integrating business and people aspects of change in organizational success. Collaboration between the people and the business results in a motivated workforce eager to bring giant results to a motivated employer, resulting in a motivating organizational climate ideal for retention, high profitability and unmatched competitive advantage in any given industry. Therefore, in the current turbulent environment, learning organization must integrate the people dimension of change with the business dimension of change to remain competitive both in service delivery, being an employer of choice and a partner of choice in business.

\section{Implications}

The study established that there is room for improvement in Safaricom's integration of dimensions of change to realize best practices in change management. The research therefore recommend that the company should encourage employees to use available avenues such as people surveys to genuinely express themselves and raise issues pertinent to improving the organization's climate to optimum productivity. The organization should keep the communication channels widely open, provide regular feedback and be seen to respond and act on the suggestion given by employees continually.

The organisation's management needs to prioritise the activities that give quick significant improvement on the relationship between the employees and the business. Employees are the ambassadors of Safaricom and therefore they ought to be in a mind-set and an emotional state to keep Safaricom way in them on and off duty. Keeping employees in regular awareness in what is cooking through regular communication before, during and after the change should be encouraged to keep the trust burning. Employees should be made aware of what is in it for them in the change process and change messengers should always be credible and full involvement of all stakeholders established before rolling out any change initiative. 
The policy makers, regulators and government in general have an opportunity to understand the dynamics of integrating people and business dimension of change for harmonization of objectives and reduce behavioural and systemic resistances in organizations. Scholars and researchers will also find the results of this study useful for further research. The findings of this study will be of value to mobile telephony industry through the turbulent times. The insights on this dimension of strategic change management by a successful MNO offers lessons and make both anticipation and management of dimensions of change a reality.

This study has provided support to the theory that organizations are open systems, which in some way or another has interaction with its surrounding environment both internal and external that contribute to the drive for change. This change would be people or systemic dimension and ADKAR model is that link between individual performance, organizational change management and business results. Internal harmonization of objectives is essential for an organization's goals to be realized. Employee's, manager's and CEO's objectives must be tied towards the corporate objective so that the entire team works in harmony in achieving the desired goals. Therefore, in an open system integrating business and people dimension of change is a firm foundation to successful organizational change management.

\section{Limitation of the Study and Suggestions for Further Research}

The research being a case study was limited to only one mobile network operator. This means that information from other players was not included in the study and therefore the findings and conclusion made may be unique to Safaricom only yet the industry is not monopolistic hence it may not be sufficient to generalize the findings at this stage on integrating people and business dimension of change in mobile telephony industry. With the same conceptualization a similar research should be replicated in another mobile network operator to provide a different context so as to interrogate and verify the results found in this study for purposes of obtaining an across industry conclusion.

Since factors and catalyst of performances could be similar across service industry a similar research is recommended to be done in an organization of any other service industry other than in mobile telephony industry. This will enable scholar to ascertain the impact of integrating people and business dimension of change in service industry by comparing the studied industry with results obtained for studies made in mobile telephony industry.

\section{Acknowledgements}

With reverence we would like to thank the almighty God for good health, His grace and blessing through the entire period of the research and report writing. We are greatly indebted to administration and the management of the School of Business, University of Nairobi for facilitating the study. Special thanks go to the Graduate Business Studies and the MBA Coordination Offices for the direct facilitation of the study. Our great appreciation goes to all the interviewees at Safaricom Kenya Limited for sparing their valuable time to honestly and patiently answer the interview questions. This study would not have succeeded without their cooperation and informative responses.

\section{References}

Airtel (2014). Equity bank unveils MVNO strategy and rollout plan. Retrieved from: http://africa.airtel.com/wps/wcm/connect/africarevamp/kenya/home/about/media-room/pressreleases/may-26-2014. [Accessed on 27/07/2014]

Alkaya, A., \& Hepaktan, C. E. (2003). Organizational change. Yönetim ve Ekonomi: Celal Bayar Üniversitesi İktisadi ve İdari Bilimler Fakültesi Dergisi, 10(1), 31-58.

Ansoff, H\& McDonnell, E. (1990). Implanting Strategic Management. Upper Saddle River, New Jersey: Prentice Hall.

Bainbridge, C. (1996). Designing for change: A practical guide for business transformation. New York: John Wiley.

Bastedo, M. N. (2006). Open systems theory. The Sage encyclopedia of educational leadership and administration. Thousand Oaks, CA: Sage.

Boohene, R., \& Williams, A. A. (2012). Resistance to organisational change: A case study of Oti Yeboah Complex Limited. International Business and Management, 4(1), 135-145.

Burnes, B. (2009). Managing change ( ${ }^{\text {th }}$ ed.). Edinburgh Gate: Pearson Education Limited. 
Cabrey, S.T., Haughey, A. (2014). Enabling organizational change through strategic initiatives. PMI's Pulse of the profession in-depth report: Project Management Institute.

Certo, S. C., Certo, S. T., \& Barman, S. (2009). Modern management: Concepts and skills. Pearson Education International.

Chabossou, A., Stork, C., Stork, M., Zahonogo, Z. (2008). Mobile telephony access and usage in Africa. Southern African Journal of Information Communication 9: 17-41.

Creasey, T. (2007). Defining change management. Prosci Learning Center.

Cummings, G.T., Worley G.C. (2009). Organizational development and change. ( $9^{\text {th }}$ ed.): South-West Cengage learning.

Cutajar, M. (2010). Open systems approach to management.

Deloitte, GSMA. (2011). Mobile telephony and taxation in Kenya.

Gichangi, E. (2011). Strategic responses by Safaricom to the dynamic business environment. (Unpublished MBA Project), School of Business University of Nairobi.

Harich, J. (2010). Change resistance as the crux of the environmental sustainability problem. System Dynamics Review, 26(1), 35-72.

Hiatt, J. M. (2006). ADKAR: A model for change in business, government and our community. Prosci Learning Center.

Hiatt, J.M. and Creasy, T.J. (2003). Change management: The people side of change. Colorado: Prosci research.

Ide-Jetro (n.d). Africa growing enterprises. Retrieved from IDE-JETRO website http://www.ide.go.jp/English/Data/Africa_file/Company/kenya03.html [Accessed on 27/07/2014]

Kaplan, R. S. (2007). What to Ask the Person in the Mirror. Harvard Business Review 85(1)

Kaplan, R. S., \& Norton, D. P. (2006). How to implement a new strategy without disrupting your organization. Harvard Business Review 84 (3)

Kargar, J., \& Parnell, J.A. (1996). Strategic planning emphasis and planning satisfaction in small firms: An empirical investigation. Journal of Business Strategies 13, no. 1.

Kisienya, L. (2012). Strategic responses to competitive environment by Mobile Telephony firms in Kenya. (Unpublished MBA project report) School of Business University of Nairobi.

Kotter, J.P. (1982). The general manager. New York: Free Press.

Kotter, J.P. (1995). Leading Change: Why transformation efforts fails. Harvard Business Review 75, no. 2.

Kotter, J. P. (1996). Leading change. Harvard Business School Press: Boston, MA, USA.

Kotter, J. P. (2001). What leaders really do. Harvard Business Review 79, no. 11.

Lange P. (2014). Market research reports: Telecommunication research. http://www.marketresearchreports.com/ paul-budde-communication-pty-ltd/kenya-telecoms-mobile-broadband-and-forecasts [Accessed on 6th August 2014].

Lawler, E. E., \& Worley, C. G. (2006). Built to change: Stanford University.

Lewin, K. (1951). Field theory in social science. New York: Harper \& Row.

Lovel, R. (1980). Adult learning. London: Croom Helm.

Mayo, E (1933).The human problems of industrial civilization. Macmillan: New York, USA.

Muema, P.N(2013). Strategic change management practices and challenges at Safaricom Limited, Kenya. (Unpublished MBA project report), School of Business University of Nairobi.

Muir, J. (1911). My First Summer in the Sierra.Boston: Houghton Mifflin.

Mullins, L.J.(1993). Management and organizational behavior.( $3^{\text {rd }}$ ed.). London:Pitman

Mullins, L..J (2007). Management and organisational behaviour. (8th ed.). Harlow: Prentice Hall.

Mungai, B. W. (2011). People dimension in managing change at Kenya Power and Lighting Company. (Unpublished MBA project report), School of Business University of Nairobi.

Murugi, M. F. (2013). Human dimension of change management in Universities in Kenya. (Unpublished MBA project report), School of Business University of Nairobi.

Musau, R.M. (2012). Change management at Safaricom Limited. (Unpublished MBA project report), School of Business University of Nairobi.

Nachmias, D. \& Nachmias, C. (1976). Content analysis. In Research methods in the social sciences ,UK: Edward Arnold.

Nadler, D. A. (1998). Champions of change: How CEOs and their companies are mastering the skills of radical change. San Francisco: Jossey-Bass. 
Ohmae, K. (1986). The Mind of Strategist. Harmondsworth: Penguin.

Olunga, V. O.(2007). Responses of Safaricom limited to changes in the Telecommunication industry in Kenya. (Unpublished MBA project report), School of Business University of Nairobi.

Pan G.C.S (2012). Change Management: The people dimension in Accounting and productivity: Answering the big questions (edited by Themin Suwardy and Gary Pan): Singapore SMU and CPA Australia.

Parumasur, S.B \& Barkhuizen, N. (2009). Organizational stress and management.

Pavlov, I.P. (1927). Conditioned reflexes. London: Oxford University Press.

PricewaterCoopers (2013). Integrating People: Engaging people to deliver deal value. PwC's Deals M\&A Integration practice.

Qiang, C. Z. W., Rossotto, C. M., \& Kimura, K. (2009). Economic impacts of broadband. Information and Communications for Development 2009: Extending Reach and Increasing Impact, 35-50. World Bank, Washington D.C.

Resende, J. (2013). Five forces driving the telecom industry. Retrieved from http://blog.wedotechnologies. com/five-forces-driving-the-telecom-industry.

Safaricom annual report, (2012). Retrieved from Safaricom website https://www.safaricom.co. ke/safaricom _annual_report/

Safaricom Ltd (n.d). Our Heritage. Retrieved from http://www.safaricom.co.ke/about-us/about-safaricom/ourhistory-heritage.

Saratoga, P. (2010). Managing People in a Changing World.

Scot, W.R. (1987). Organizations: Rational, Natural and Open Systems. Engledwood Cliff: Prentice-Hall.

Senge, P. M. (2006). The fifth discipline: The art and practice of the learning organization. Random House LLC.

Skinner, B.F. ( 1974). About behaviourism. London: Cape.

Stacey, R.D. (2003). Strategic management and organisational dynamics: The challenge of complexity. Harlow: Financial Times Prentice Hall.

Stemler, S. (2001). Practical Assessment, Research and Evaluation. A peer-reviewed electronic journal. ISSN 1531-7714 : PAREonline.

Sullivan, M., Tillman, K. (2006). Driving Sustainable Change: Integrating Organizational Change Management Strategies.

Thompson, A.A., Strickland, A.J., Gamble, J.E. (2010). Crafting and executing strategy (17 ${ }^{\text {th }}$ ed.): McGrawHill/Irwin.

Todd, A. (1999). Managing Radical Change. Long Range Planning, 32(2), 237-244.

Weihrich, H., Cannice, V.M., Koontz, H. (2010). Management: A global and entrepreneurial perspective (12th ed.): Tata McGraw Hill.

Weber, R. P. (1990). Basic content analysis, (2nd ed: Newbury Park, CA.

Yin, R. K. (1994). Case Study Research-Design and Methods. Applied Social Research Method Series (5): Sage: London.

Yin, R. K. (2003). Designing case studies. Case Study Research: Design and Methods, 19-56. 